\title{
Chronology, Culture, and Climate: A Radiometric Re-evaluation of Late Prehistoric Occupations at Cape Denbigh, Alaska
}

\author{
Maribeth S. Murray, Aaron C. Robertson, and Rachel Ferrara
}

\begin{abstract}
This paper presents new data about the chronological placement of two archaeological sites at Cape Denbigh, Norton Sound, Alaska and others along the Kobuk River, Alaska. Direct radiometric dates on arrowpoints and harpoon heads indicate that selected type specimens are not always reliable temporal indicators for late prehistoric sequences in northwest Alaska and Arctic Canada. In the future new fieldwork and direct dating of artifacts and associated sediments will be necessary in order to refine culture-history sequences, evaluate the utility of artifact types as chronological indicators, and to examine the relationship between past culture change and environmental change in coastal Alaska.
\end{abstract}

\section{Introduction}

E. Understanding the prehistory of northwest Alaska $\vec{\partial}$ is confounded by a shortage of well-dated archaeह ological components, and by the temporal, functional, and cultural ambiguity of purportedly diagnostic arrowpoints and harpoon heads. These problems limit researchers' ability to untangle any relationship(s) between human behavior as reflected in the archaeological record and weather and climate episodes-occurring annually or on a larger scale reflecting decades or centuries. Following others interested in similar issues in Alaskan archaeology (Dumond 2000a, 2000b; Dumond and Griffin 2002; Gerlach and Mason 1992; Mason and Gerlach 1995a, 1995b; Mills 1994; Minc and Smith 1989; Morrison 1989, 2001), this paper presents new data bearing on the chronological placement of archaeological sites at Cape
Denbigh. The relative utility of certain artifact types as unambiguous chronological indicators is evaluated in light of new radiocarbon dates on artifacts from Nukleet and Iyatayet at Cape Denbigh. This paper also briefly considers the possible cooccurrence of certain climate and weather episodes with possible changes in late prehistoric settlement and subsistence patterns and offers suggestions for future research.

\section{The Kobuk River Sequence and the Arctic Woodland Culture}

In $1952 \mathrm{~J}$. Louis Giddings published the results of his 1941 and 1947 archaeological and dendrochronological investigations along the Kobuk River (see Nash 2000 for a summary). Although he located over 24 archaeological sites, and reported

Maribeth S. Murray, Aaron C. Robertson, Rachel Ferrara, Department of Anthropology P.O. 757720, University of Alaska Fairbanks, Fairbanks, Alaska, 99775-7720 
on the locations of many others, Giddings

(1952:5-6) conducted his primary excavations at Ambler Island (15 houses), Onion Portage (4 houses), Ahteut (12 houses), Ekseavik (8 houses), and Kotzebue (5 houses) (Fig. 1). Based on the archaeological remains, and the dendrochronology he derived from structural timbers in house features and by sampling living trees, Giddings devised a chronological sequence for the Kobuk River, a sequence that culminated in a pattern that was neither Eskimo or Athabascan but rather "a firmly entrenched inland culture" that combined elements of both, but was intermediate to neither (Giddings 1952:2). This he called the "Arctic Woodland Culture."

Each of the five major sites in Giddings' Kohuk sequence exhibits seasonal and functional dif扁rences to varying degrees, and in addition reflect differences in specific aspects of material culturef Giddings (1964:28-29) summarizes these diffêrences as follows:
Ambler Island (A.D. 1700-1760): a forest site; emphasis on caribou hunting and seasonal fishing; semi-nomadic, temporary winter pithouses; absence of the implements of sea mammal hunting; dog traction present.

Intermediate Kotzebue (A.D. 1500-1550): a coastal site at the Kobuk River mouth; harbor sealing, fishing, and caribou hunting; permanent winter pit-houses; built-up sledge but no evidence for dog traction.

Old Kotzebue (A.D. 1380-1420): Middle Kobuk River; the site most similar to Tigara at Point Hope and later eastern Thule culture.

Ekseavik (A.D. 1380-1420): Middle Kobuk River; same cultural affiliation as Intermediate Kotzebue but with a stronger Thule cast; sealing equipment indicating seasonal coastal residence; exploitation of the forest.

Ahteut (A.D. 1200-1250): Middle Kobuk River; permanent winter population; well-fired pottery, paddled, with curvilinear stamp and tex-

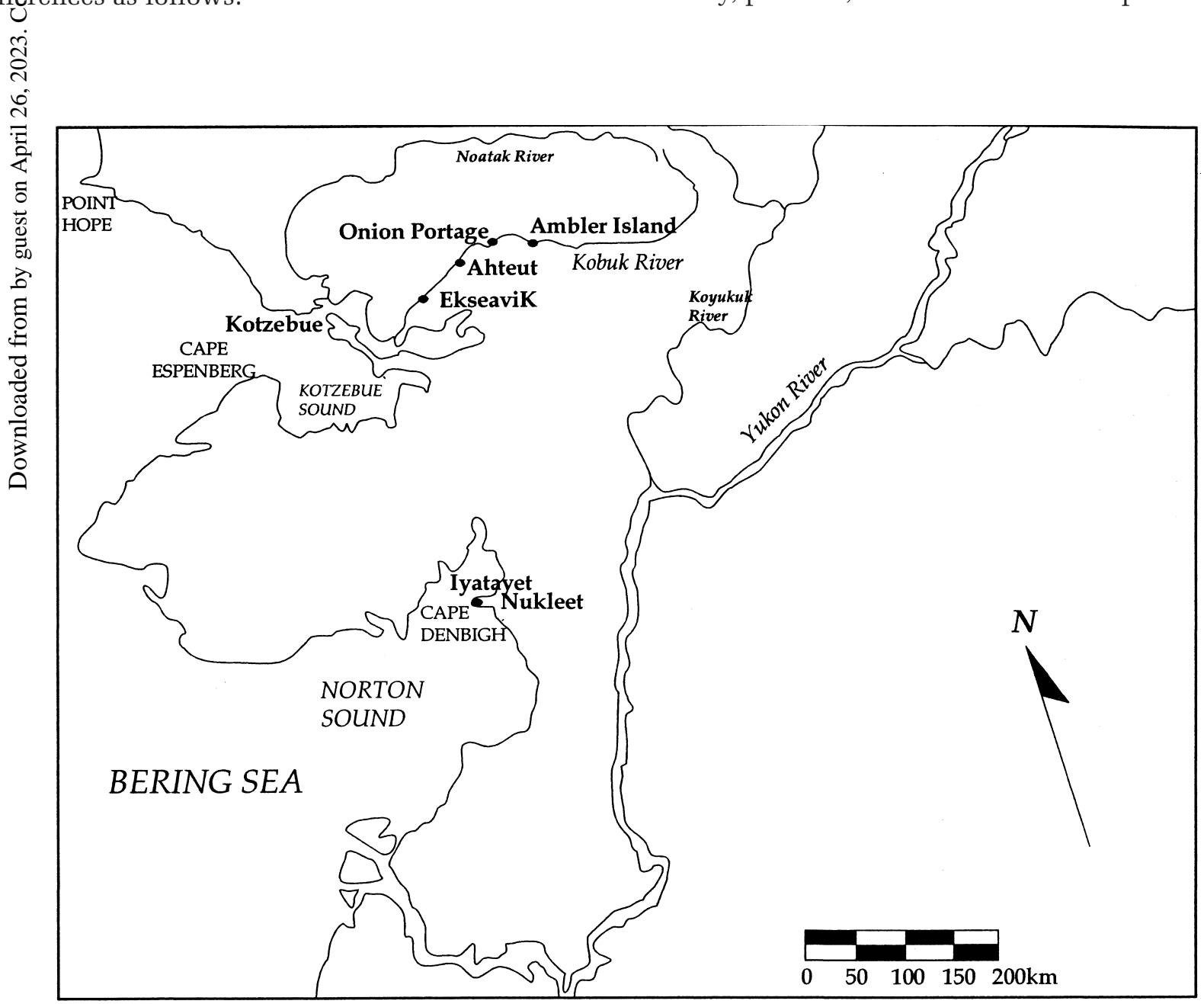

Figure 1. Map of Norton Sound and Kobuk River Area. 
tile impressed interior; full forest adaptation; sealing; culture is western Thule as at Point Hope; Early Punuk harpoon heads as at St. Lawrence Island.

Other sites thought to fit into the above sequence are located on the upper Kobuk River at Onion Portage (Giddings 1952:6), and according to Anderson (1988:134) "span the entire sequence of Arctic Woodland Culture" and "show a progressive change from seasonal use to a yearround use."

\section{Late Prehistoric Sites in Norton Sound: Nukleet and Iyatayet}

\section{Nukleet}

¿ूLocated at Cape Denbigh on the south coast of NNorton Sound, Nukleet (Fig. 1) was first recorded .0. 1930), with extensive excavations conducted in Uthe late 1940s (Giddings 1964). This is the typeisite for the Nukleet complex, a late prehistoric manifestation in this part of coastal Alaska, with îpresumed contemporaneous and related complexes along the Kobuk River and elsewhere in north Alaska, including Iyatayet, which is also lo5 cated at Cape Denbigh (Fig. 1).

The site is an accumulation of midden and thouse remains, with deposits in some areas exEceeding 2 m (Giddings 1964:11). Excavations in $\Xi 1948$ consisted of two trenches (Cuts A and B), gtwo test units (C and D), and one house feature (H1), and in 1949 a large block excavation referred Eto as either "NI" or the "1949 excavation" (Fig. 2).

Because the deposits were frozen, excavation in all units proceeded in arbitrary 6-inch levels. Natural stratigraphic layers are recorded in narrative form, and on the profiles of Cuts A and B (Giddings 1964:15). Over 6,000 items were recovered and catalogued with provenience information that details the unit and the level of recovery (University of Alaska Museum catalogue).

At Nukleet, Giddings viewed certain artifact types as both chronological and cultural indicators (Giddings 1964). Among these are harpoon heads, harpoon dart heads, and antler arrowpoints. There are ten different forms of harpoon heads and eight are affiliated with variants from sites elsewhere in northwest Alaska and especially with the collections from the Kobuk River (Giddings 1964).

In addition to the harpoon heads, there are sixteen kinds of arrowpoints. Giddings (1964) notes that the arrowpoints underwent one major morphological transition, from a rounded shoulder above the stem to an angular shoulder. This shift parallels an apparently time-sensitive transition in arrowpoint form at Point Hope (Fig. 1) where rounded shoulder forms are thought to predate angular shouldered forms (Larsen and Rainey 1948). Nukleet arrowpoints are also similar to types found in the Kobuk River sites, as are some of the harpoon dart heads.

Artifact types and styles vary and co-vary in frequency as one moves from the upper to lower deposits. Giddings (1964) argued that the artifacts in the lower levels of Cut B are easily distinguished from those in the upper levels, and from all of the artifacts in Cut A. He further suggested that these variations, including the presence or absence of given types, indicated a "more or less continuous occupation" of about 700 years, from the twelfth to the eighteenth centuries (Giddings 1964:113). Moreover, all but the lowest levels in Cut B were thought to correspond to counterparts in the dendrochronologically dated Kobuk River sequence (Giddings 1964:116). Arbitrary levels 1 through 4 (Giddings 1964:Fig. 5 and 8) in all excavated areas equate stylistically with the Intermediate Kotzebue period (A.D. 1550 to abandonment). However, lower levels differ from each other across the site. Ekseavik and Old Kotzebue (A.D. 1380-1420) periods are represented in Cut A in levels 5 through 12 (Giddings 1964:Fig. 5), and in Cut B in level 5 to the top of the dense midden (Giddings 1964:Fig. 8). The dense middens in Cut B, particularly in sections 3 and 5 (Giddings 1964:Fig. 8), correspond to Ahteut (A.D. 1200-1250), while the lowest parts of these deposits have no exact Kobuk counterpart and should predate A.D. 1250.

\section{Iyatayet}

Iyatayet was first investigated in 1948 (Fig. 3). The site is an accumulation of house and midden features on two terraces bisected by Iyatayet Creek (Giddings 1964:Fig. 28 and 31). Remains are associated with three archaeological complexes: the Denbigh Flint Complex, the Norton Culture, and the Arctic Woodland Culture as manifest in Nukleet-type deposits found across the site. Although the objective of the fieldwork at Iyatayet was to recover earlier Norton and Denbigh materials, and even though efforts were made to avoid the Nukleet deposits (Giddings 1964:119), there is still a substantial amount of data relating to these and some of this information is considered in subsequent sections. 


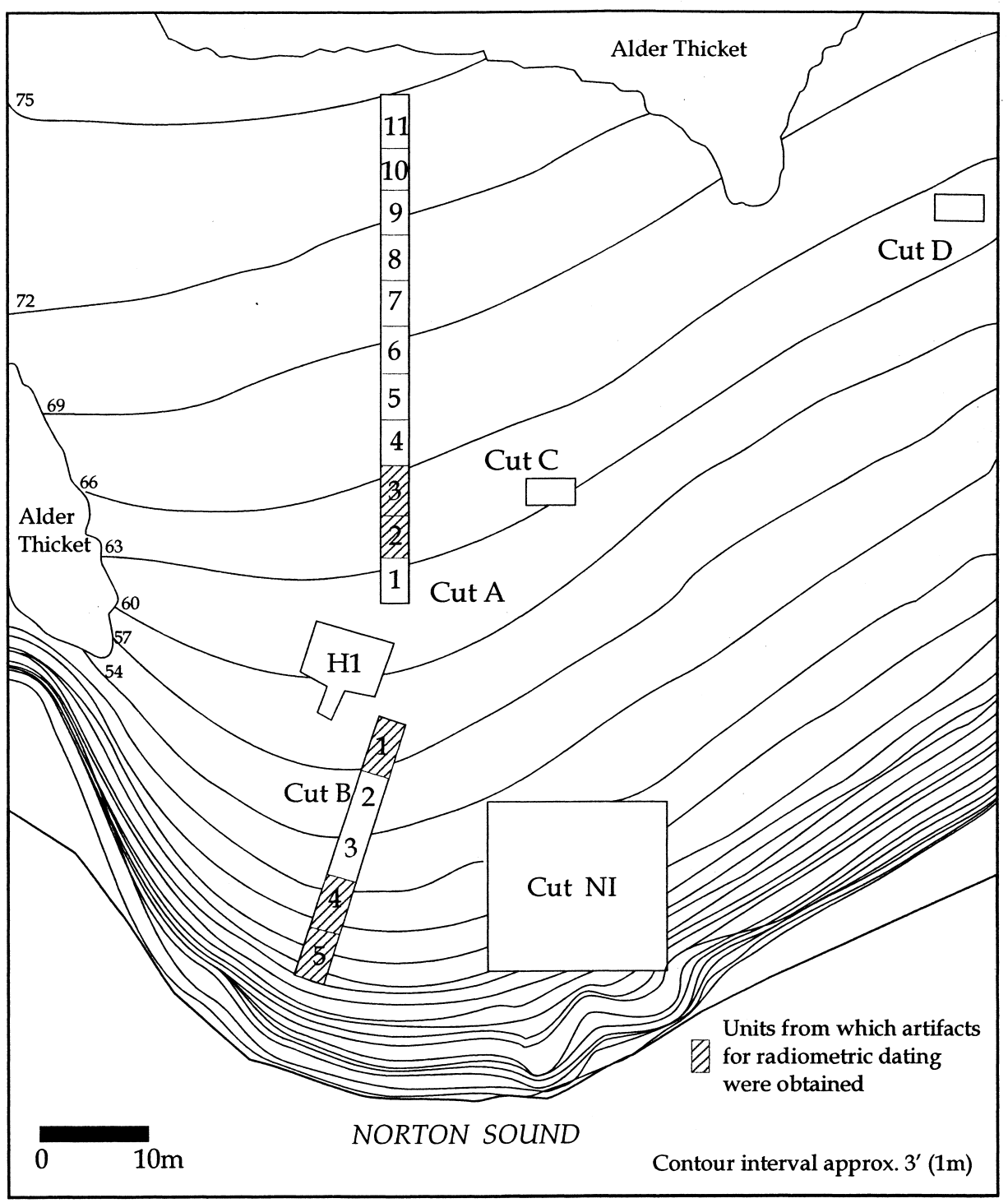

Figñe 2. Nukleet-Giddings' excavation units (after Giddings 1964:12, Fig. 4).

During the 1948 field season, Giddings opened fifteen $6 \times 10$ foot excavation units, including the area of House 1. In 1949 new cuts, including $\mathrm{K}, \mathrm{O}$, and $\mathrm{Z}$, were added and others, (e.g., A and E) were expanded. Efforts in 1950 concentrated on delineating Denbigh and excavations focused on Cut Z and Cut PE were opened. Small excavations occurred in 1952 in Cuts Z-5 and R. These were designed to obtain carbon samples for radiometric dating and to examine solifluction lobes (Giddings 1964:119-137) (Fig. 3).

The preservation of the Nukleet deposits at Iyatayet is not as good as at Nukleet itself, and in general the site is poorly stratified (Giddings 1964:119), possibly because of solifluction although this is not clear in Giddings' 1964 publication.
Nevertheless, excavation did follow the inferred natural and cultural levels. Even so, artifact provenience is problematic because only the cut and levels were recorded. The location of artifacts within specific units in particular cuts, the unit number, and the depth below surface were apparently not recorded, or if they were, these data are not readily available.

\section{New Radiometric Dates from Nukleet and Iyatayet}

In an effort to begin to develop a better and more reliable radiocarbon chronology for archaeological sites in Norton Sound, and as part of an ongoing UAF radiocarbon dating program designed to ad- 


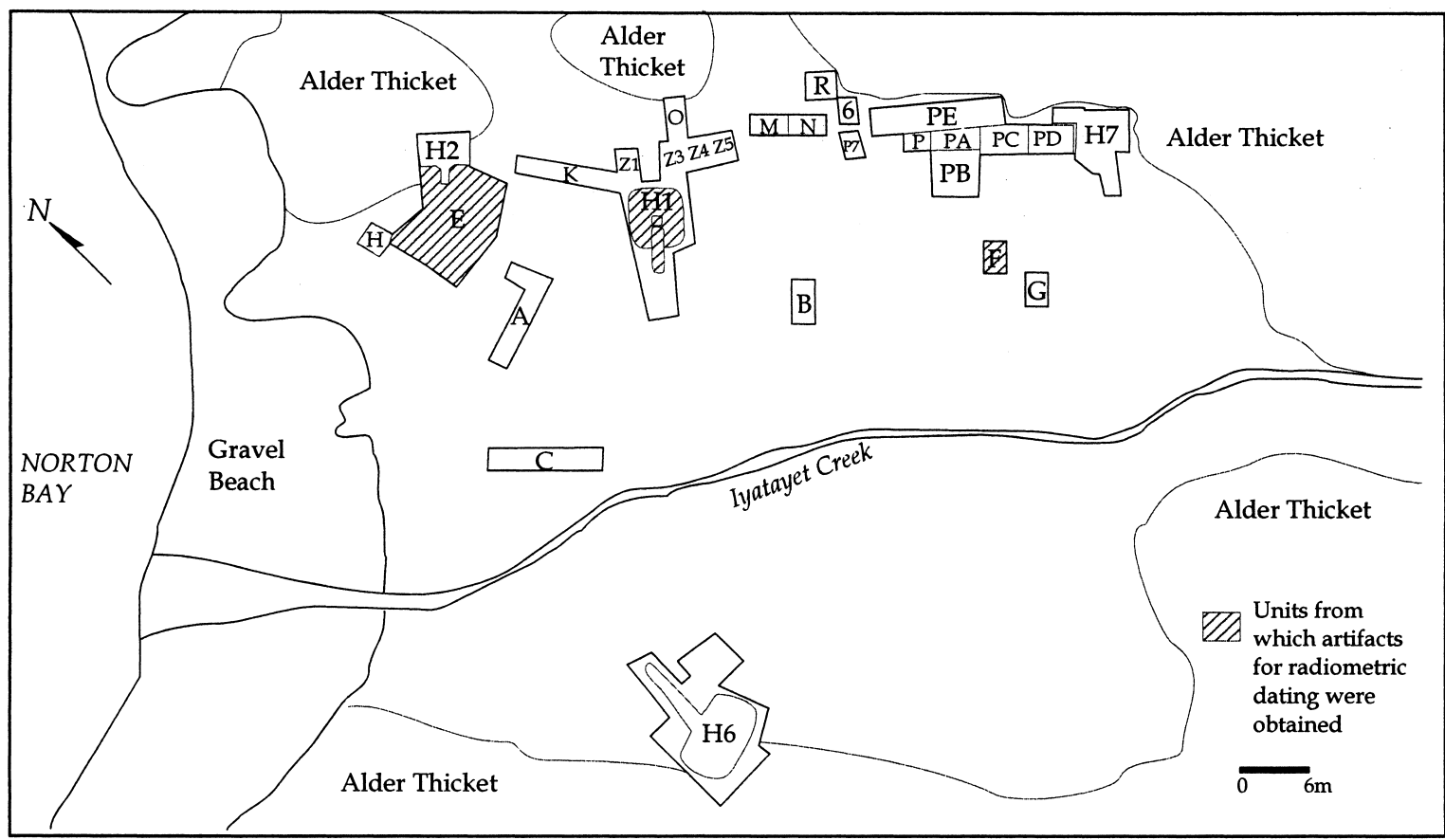

Figure 3. Iyatayet-Giddings' excavation units (after Giddings 1964:122, Fig. 31).

ते

กิ

Dress a variety of issues in Arctic prehistory (GerLach and Mason 1992; Mason and Gerlach 1995a, ธี 1995b; Mills 1994; Gerlach, personal communica范 tion 1999), ten artifacts considered by Giddings कo $(1952,1964)$ and others (Anderson 1988; Collins 1930, 1937; Ford 1959; Larsen and Rainey 1948; ō McCullough 1989: Mathiassen 1927; Morrison 2001; Stanford 1976; and Whitridge 1999) to be diagnostic of particular late prehistoric and early historic Eskimo occupations in Alaska and parts of Arctic Canada were submitted to Beta Analytic for AMS radiocarbon dating (see Tables 1 and 2).

Seven artifacts are from Nukleet and are specifically considered by Giddings to be diagnostic of different phases of occupation on the Kobuk River (Giddings 1952). Each is a member of a suite of artifact types used to infer stability and change in occupations at Nukleet. The remaining three artifacts are from Iyatayet and include one each of Nukleet, Thule, and Ekseavik-styles. These, among other items, were used to identify a Nukleet affiliation for the upper levels at that site (Giddings 1964).

\section{AMS Radiometric Dates from Nukleet}

Three radiocarbon assays were run on artifacts from Cut A, the $160 \times 6$ foot trench shown in Figure 2 . Two antler harpoon heads $(2657,2651)$ and one antler arrowpoint (2543) were recovered from Units 2 and 3. Another four radiocarbon assays were conducted on antler artifacts from Cut B, the $50 \times 6$ foot trench located immediately south of Cut A (Fig. 2). These items, one harpoon dart head (2945), two arrowpoints $(2555,2573)$, and one harpoon head (2685), were recovered from Units 1, 4, and 5. Efforts were made to date materials from both the upper, middle, and lower levels of both cuts. Stratigraphic details, including the locations of dated artifacts, are presented in Figure 4, and artifacts are illustrated in Figure 5. The results are discussed below in stratigraphic order of occurrence from upper to lower levels and are summarized in Table 1.

\section{Cut $A$}

The "Ekseavik-type” antler harpoon head (2657) (Fig. 5a), from level 2, at 6-12 inches below surface, is dated at $480 \pm 40$ B.P. (A.D. 1404-1469 cal 2 sigma), while the "Ekseavik-type" antler arrowpoint (2543) (Fig. 5b) is dated to $380 \pm 40$ B.P. (A.D. 1440-1640 cal 2 sigma). This item was recovered from levels 3-4, or 12-24 inches below surface. This slight reversal is considered insignificant because there is overlap between the dates at the twosigma range and there is no evidence in the stratigraphic profile for changes in the nature of the deposit between level 2 and levels 3-4 (see Fig. 3).

The third date from Cut A, on an "Intermediate Kotzebue-style” antler harpoon head (2651), is 

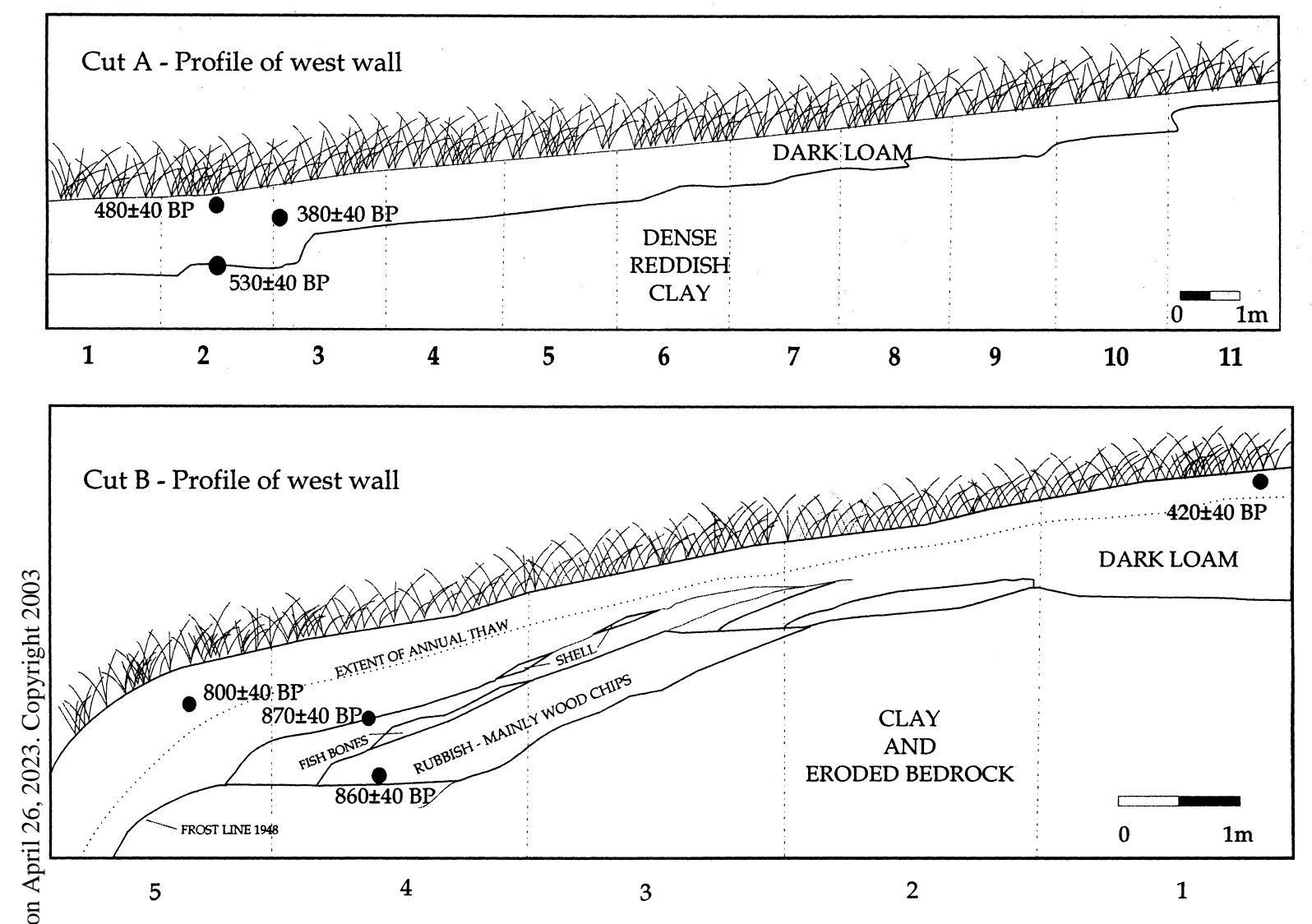

Figure 4. Nukleet-Profiles of Cuts A and B showing location of radiometrically dated artifacts (profiles after Giddings 1964: Fig. 5 insert, and p. 20, Fig. 8).

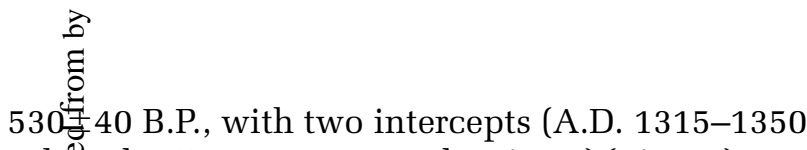

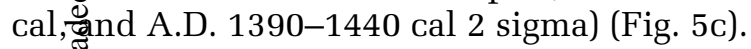
Thi: item was recovered from 60-66 inches below surfînce.

ڤ̂Ekseavik-style artifacts were thought by Giddings $(1952,1964)$ to date from A.D. 1380-1420, while intermediate Kotzebue types were thought to date from A.D. 1500-1550. To the authors' knowledge the dates presented here are the first direct dates on artifacts that have been considered type styles for Ekseavik and intermediate Kotzebue. The Ekseavik type harpoon head (2657) dates very close to, but slightly younger than Giddings' estimation of A.D. 1380-1420, while the Ekseavikstyle arrowpoint (2543) with two intercepts, could be as much as 200 years younger. The Intermediate Kotzebue-style harpoon head (2651) is about 100 years older than expected.

\section{Cut B}

Giddings (1964) suggested that Nukleet levels 1-5 in Cut B represented a period dating from Intermediate Kotzebue (A.D. 1500-1550) to aban-

donment. An "Ekseavik/Old Kotzebue-style" harpoon dart head (2945) (Fig. 5d) from Level 1-2 that was submitted for radiocarbon dating returned a date of $420 \pm 40$ B.P. (A.D. $1420-1520 \mathrm{cal}$ 2 sigma and A.D. $1440-1480 \mathrm{cal} 2$ sigma). This date overlaps with the new radiocarbon dates on the Ekseavik-style artifacts from the upper levels of Cut A discussed above, and like those dates may overlap with or be somewhat younger than Giddings' estimated age for Ekseavik/Old Kotzebue style materials more generally. However Giddings (1964) assigned the upper levels of both Cuts A and B to Intermediate Kotzebue (A.D. 1500-1550), assuming dates that are younger than the dated artifacts discussed here. This suggests that current models of artifact culturaltemporal affiliation need to be revised, and that many "temporally diagnostic" artifacts co-occur across time and space (Gerlach and Mason 1992; Mason and Gerlach 1995a, 1995b).

According to Giddings, levels 5 down through to the top of the dense midden correspond temporally and culturally to Ekseavik and Inter- 


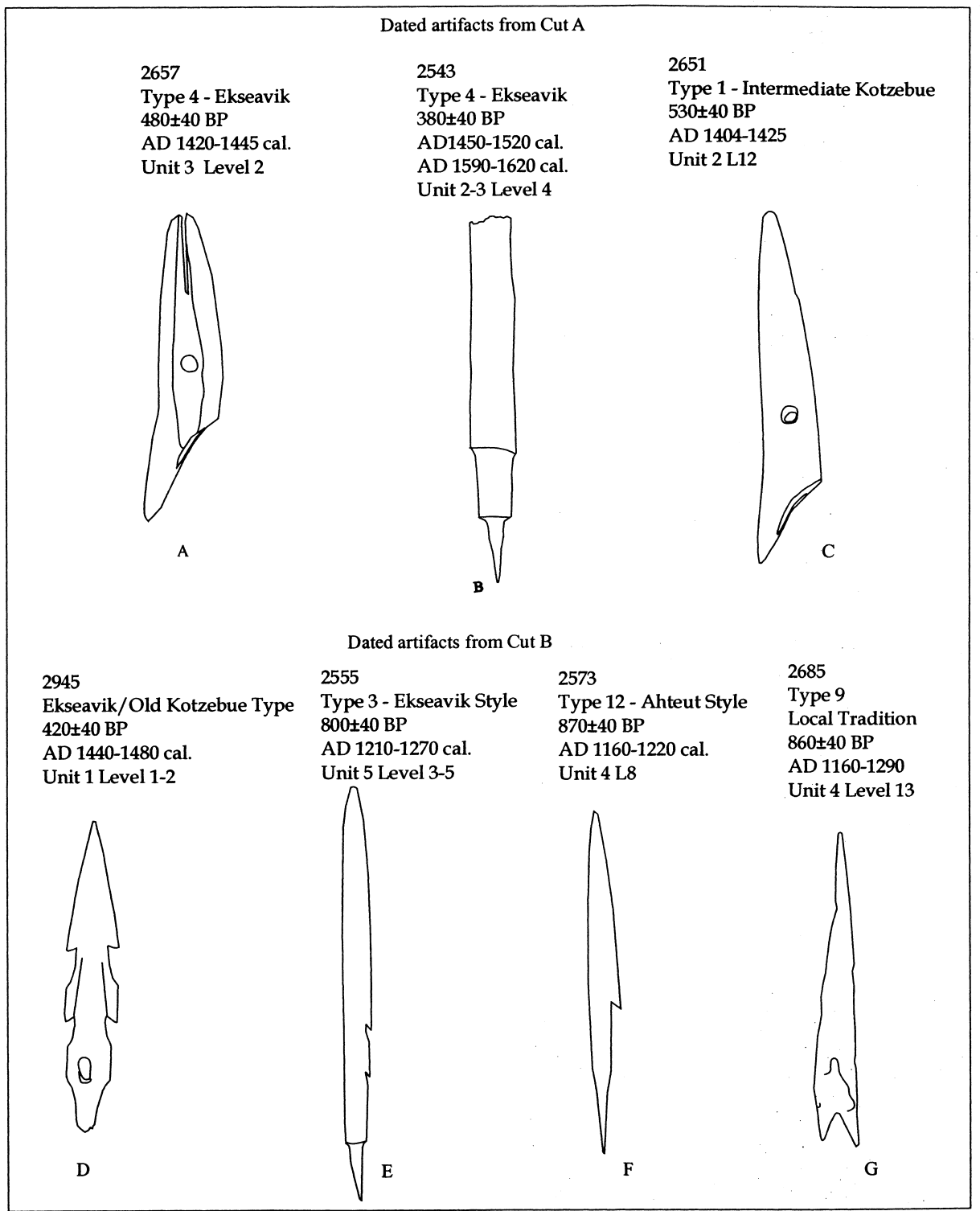

Figure 5. Radiometrically dated artifacts from Nukleet (not to scale).

mediate Kotzebue (A.D. 1400-1550). Unfortunately, it is not possible to determine exactly where the "dense midden" starts, nor what it includes. The midden was located immediately beneath the shell stratum (Giddings 1964:21), but this is not indicated on the stratigraphic section (Giddings 1964: Fig. 8). Moreover, it is not clear if the midden includes the fish bone stratum shown on the section, although Giddings indicates that it did contain streaks of shell and fish bones (refer to Fig. 4). Materials within the dense midden are thought to correspond to Ahteut (A.D. 1200-1250) and earlier periods. Material that lay above all potential strata comprising the dense midden was dated in order to obtain information from the presumed Ekseavik/Intermediate Kotzebue levels, as was material that certainly lay within and beneath the midden in order to date presumed Ahteut and earlier levels. The "Ekseavik-style" arrowpoint (2555) (Fig. 5e) recorded as recovered from level 3-5 returned a radiocarbon date of $800 \pm 40$ B.P. (A.D. 1180-1280 cal 2 sigma). This is several hundred years earlier than expected given Giddings' estimation. From level 8, within the dense midden, the "Ahteut-style" arrowpoint (2573) dates to $870 \pm 40$ B.P. (A.D. 1040-1260 cal 2 sigma). This 


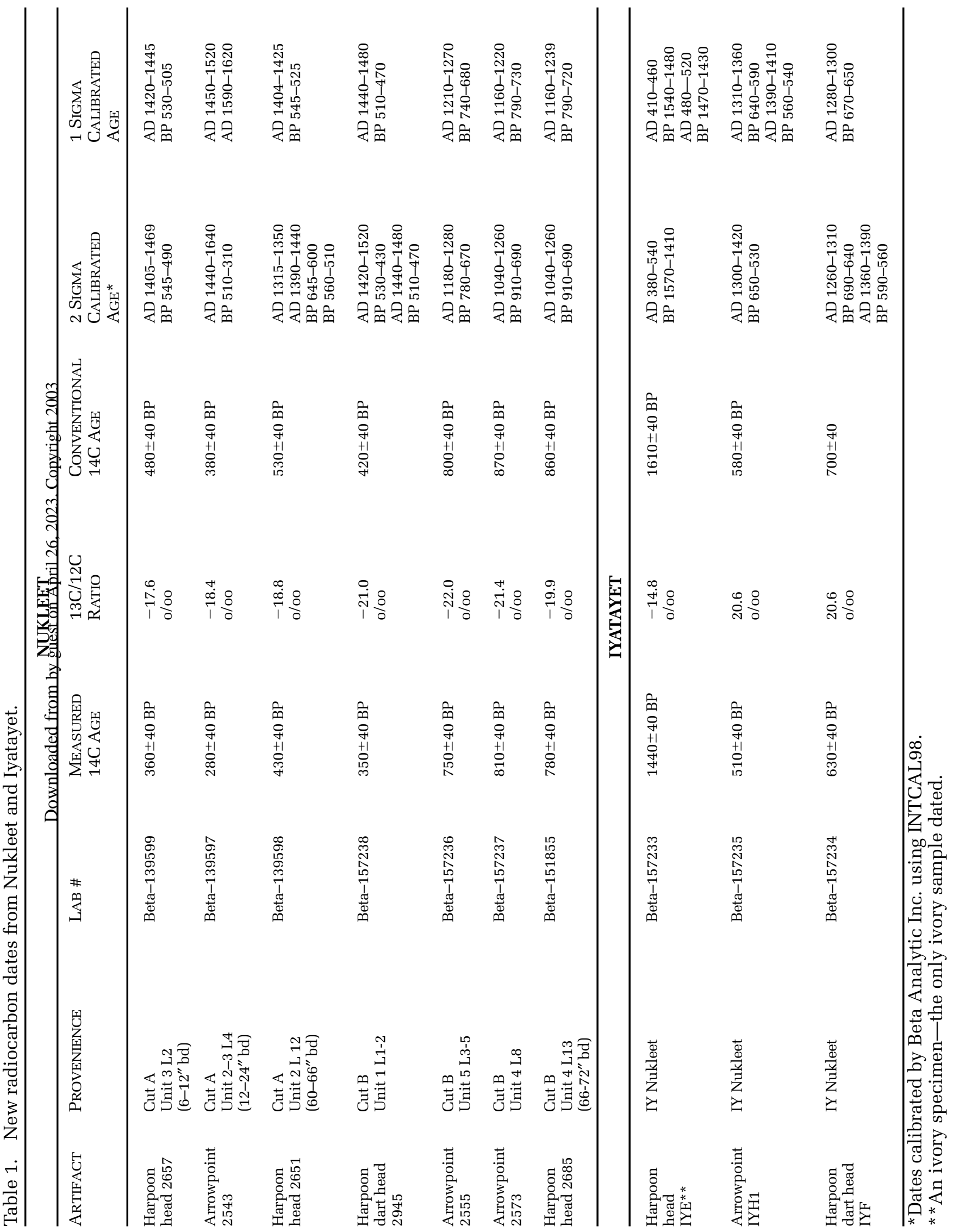


Table 2. Radiometrically dated artifact types from Nukleet and Iyatayet.

\begin{tabular}{|c|c|c|c|c|}
\hline $\begin{array}{l}\text { Artifact } \\
\text { Type* }\end{array}$ & Description & Affiliation & $\begin{array}{l}\text { Giddings' } \\
\text { Date }\end{array}$ & $\begin{array}{l}\text { Conventional and } \\
\text { Calibrated 14C Age }\end{array}$ \\
\hline $\begin{array}{l}\text { Harpoon head } \\
2657 \\
\text { Type } 4\end{array}$ & $\begin{array}{l}\text { Closed socket } \\
\text { Bladed head } \\
\text { Raised Design }\end{array}$ & $\begin{array}{l}\text { Ekseavik } \\
\text { type }\end{array}$ & AD 1380-1420 & $\begin{array}{l}480 \pm 40 \text { BP } \\
\text { AD } 1420-1455 \\
\text { Beta } 139599\end{array}$ \\
\hline $\begin{array}{l}\text { Arrowpoint } 2543 \\
\text { Type } 4\end{array}$ & $\begin{array}{l}\text { Barbless } \\
\text { Square shoulder } \\
\text { Conical tang }\end{array}$ & $\begin{array}{l}\text { Ekseavik } \\
\text { type }\end{array}$ & $\mathrm{AD} 1380-1420$ & $\begin{array}{l}380 \pm 40 \mathrm{BP} \\
\mathrm{AD} 1450-1520 \\
\mathrm{AD} 1590-1620 \\
\text { Beta } 129597\end{array}$ \\
\hline $\begin{array}{l}\text { Harpoon head } \\
\text { Type } 1\end{array}$ & $\begin{array}{l}\text { Closed socket } \\
\text { Plain }\end{array}$ & $\begin{array}{l}\text { Intermediate } \\
\text { Kotzebue }\end{array}$ & $\mathrm{AD} 1500-1550$ & $\begin{array}{l}530 \pm 40 \mathrm{BP} \\
\mathrm{AD} 1404-1425 \\
\text { Beta } 139598\end{array}$ \\
\hline $\begin{array}{l}\text { Harpoon dart } \\
\text { head } 2945\end{array}$ & Barbed & $\begin{array}{l}\text { Ekseavik, } \\
\text { Old Kotzebue } \\
\text { type }\end{array}$ & AD 1380-1420 & $\begin{array}{l}420 \pm 40 \mathrm{BP} \\
\text { AD } 1440-1480 \\
\text { Beta } 157238\end{array}$ \\
\hline $\begin{array}{l}\text { Arrowpoint } 2573 \\
\text { Type } 12\end{array}$ & $\begin{array}{l}\text { Single barb } \\
\text { Conical tag }\end{array}$ & Ahteut type & $\mathrm{AD} 1200-1250$ & $\begin{array}{l}860 \pm 40 \mathrm{BP} \\
\mathrm{AD} 1160-1220 \\
\text { Beta } 157237\end{array}$ \\
\hline $\begin{array}{l}\text { E్ Arrowpoint } 2555 \\
\text { EType } 3\end{array}$ & $\begin{array}{l}\text { Double barb } \\
\text { Square shoulder } \\
\text { Conical tang }\end{array}$ & $\begin{array}{l}\text { Ekseavik } \\
\text { type }\end{array}$ & $\mathrm{AD} 1380-1420$ & $\begin{array}{l}800 \pm 40 \mathrm{BP} \\
\mathrm{AD} 1210-1270 \\
\text { Beta } 157237\end{array}$ \\
\hline $\begin{array}{l}\text { Harpoon head } \\
32685 \\
2 \text { Type } 9\end{array}$ & Double spur & $\begin{array}{l}\text { Local } \\
\text { tradition }\end{array}$ & $\begin{array}{l}\mathrm{AD} 1250 \text { or } \\
\text { earlier }\end{array}$ & $\begin{array}{l}860 \pm 40 \text { BP } \\
\text { AD 1160-1290 } \\
\text { Beta } 151855\end{array}$ \\
\hline $\begin{array}{l}\text { Harpoon head } \\
\text { IYE } \\
\text { Thule Type } 2\end{array}$ & $\begin{array}{l}\text { Self bladed } \\
\text { Open Socket }\end{array}$ & Thule style & $\begin{array}{l}\text { none } \\
\text { provided }\end{array}$ & $\begin{array}{l}1610 \pm 40 \\
\text { AD 410-460 } \\
\text { AD 480-520 } \\
\text { Beta } 157244\end{array}$ \\
\hline $\begin{array}{l}\text { क्रे Harpoon dart } \\
\text { onhead } \\
\text { DIYF }\end{array}$ & $\begin{array}{l}\text { Barbed } \\
\text { Open Socket }\end{array}$ & $\begin{array}{l}\text { Ekseavik/Cook } \\
\text { Inlet style }\end{array}$ & AD 1380-1420 & $\begin{array}{l}700 \pm 40 \mathrm{BP} \\
\mathrm{AD} 1280-1300 \\
\text { Beta } 157235\end{array}$ \\
\hline $\begin{array}{l}\text { Arrowpoint IYH1 } \\
\text { Type } 13\end{array}$ & $\begin{array}{l}\text { Barbed } \\
\text { Conical tang }\end{array}$ & "old style" & $\begin{array}{l}\text { none } \\
\text { provided }\end{array}$ & $\begin{array}{l}580 \pm 40 \text { BP } \\
\text { AD } 1310-1360 \\
\text { AD } 1390-1410 \\
\text { Beta } 157238\end{array}$ \\
\hline
\end{tabular}

*Following Giddings 1964

range, although it encompasses expected Ahteut dates, suggests that at least some forms are longerlived than expected. Finally from level 13, within the rubbish-wood chip deposit, a harpoon head (2685), designated by Giddings (1964) as local "pre-Ahteut" style (Fig. 5f), dates to $860 \pm 40$ B.P. (A.D. 1040-1260 cal 2 sigma), the same as the date derived from the "Ahteut-style" arrowpoint.

\section{Discussion}

The seven radiocarbon dates from Cuts A and B provide some clues as to the duration of site formation at Nukleet. They suggest the possibility of an initial period of formation between roughly A.D. 1000-1300, possibly a short hiatus between the end of the thirteenth century and the start of the fifteenth century, and a possible second phase of site formation concentrated in the fifteenth century. All the radiocarbon dates correspond to dendrochronological dates assigned to Ekseavik and Intermediate Kotzebue (A.D. 1380-1550) on the Kobuk River, and with respect to Giddings' chronology for Nukleet, suggest an occupation about 400 years shorter than his original estimate of roughly 700 hundred years from the twelfth to the eighteenth century. The two dates from the upper levels of both cuts suggest the possibility of site abandonment several hundred years prior to the eighteenth century.

The dates from Cuts A and B become increasingly older as one moves toward the bottom of the deposits, but they are generally earlier than those suggested by Giddings' (1964) comparison to the 
Kobuk River sites by an average of about 200 years and possibly even more. Unfortunately an approximate start date for deposition in the area of Cut B has not yet been defined. Subsequent to obtaining dates on the artifacts discussed here, a discrepancy between the artifact inventory and the stratigraphic section of Cut B was discovered. Giddings' cross-section (1964:20, Fig. 8) allows for 14 6-inch excavation levels. However, provenience on artifacts accessioned in the University of Alaska $\mathrm{Mu}-$ seum records 20 excavation levels. The stratigraphic section for Cut A was prepared in 1948 and shows excavations for that year only. These stopped at the permafrost. The remaining six levels were thawed and excavated in 1949 (Giddings 1964:22), but were apparently never added to the profile. Future dating efforts should inc蛋de some materials from the lowest part of this depesit.

More important than potentially illuminating the furation of site formation at Nukleet, these dates highlight the fact that while Giddings dendrogêhronology may accurately estimate the dates for aुg gुnd sequence of site occupation on the Kobuk, it dộes not necessarily follow that artifact types like larlgtemporally restricted. Dendrochronology does not reveal the length of time that an artifact stylæm may have been in use and caution is advised wh面 using artifact style to place sites temporally. Thif్ point is examined again below in a discussioftof time, space, and diagnostic artifacts.

\section{Dałes from Iyatayet}

Thr artifacts from the Nukleet component at Iyatayet. One is from Cut E, where there was clear separation between Nukleet and earlier materials (Giddings 1964:123, and Fig. 36); one is from Cut F, where the upper level "contained quantities of rotten wood, suggesting nearness to a Nukleet period structure . .." (Giddings 1964:124); and one is from House 1, which was completely excavated and thought to date to the last period of site occupation (Giddings 1964:124, and Figs. 32, 33, 34, and 35 ). The units from which the artifacts were obtained are shown on Figure 3 and the dating information is summarized in Tables 1 and 2. The Nukleet layer shows no evidence of freeze-thaw disturbance but there are some items displaced from the earlier Norton and Denbigh occupations, probably as a result of Nukleet period construction activities (Hopkins and Giddings 1953:22).
An ivory Thule Type 2 harpoon head (IYE001) (Fig. 6a) from Cut E was one of only a few diagnostic types available to the authors from this location. This item returned a date of $1610 \pm 40$ B.P. (A.D. 410-460 cal 2 sigma, and A.D. 480-520 cal 2 sigma). The dating of marine materials is an issue for archaeology because of the marine reservoir effect that causes marine samples to appear much older than equivalent terrestrial samples. This is particularly a problem in the Arctic, where suitable terrestrial materials may be scarce and where researchers have long recommended caution when interpreting dates on marine samples for archaeological purposes (cf. Arundale 1981; McGhee and Tuck 1976). The search for a reservoir correction factor or factors for the arctic regions of North America is ongoing (see, for example, Dyke et al. 1996). Recently Dumond and Griffin (2002) have suggested, based on several series of paired radiometric determinations on marine (shell and mammal), and terrestrial materials (charcoal, wood, or grass), that the reservoir effect in the Bering Sea may range from 450 to 750 years. Using the results from 14 paired samples of marine mammal and terrestrial materials a correction factor of $735 \pm 20$ years is suggested (Dumond and Griffin 2002:83). If this correction is applied to the radiometric date on the Thule type 2 ivory harpoon head (IYE-001) from Iyatayet, it adjusts the date to 875 \pm 40 B.P. (A.D. 1035-1115), which is consistent with the earliest dated artifact from Nukleet, an Ahteut/Thule style arrowpoint (2573) (870 440 B.P. [A.D. 1040-1256 cal 2 sigma]), and with early Thule materials from elsewhere, including a directly dated suite of five late Birnirk/early Thule antler harpoon heads (A.D. 795-1135 cal 2 sigma) from Birnirk and Esetqua in the Barrow area of Alaska (Morrison 2001:80). However, despite this apparent fit, the reliability of radiometric dates on marine materials, especially for the purposes of refining artifact chronologies, is questionable because of the apparent regional variability of the marine reservoir effect in the Bering Sea (cf. Dumond and Griffin 2002) and the difficulty in determining how this affects marine samples submitted for dating. Thus this date is excluded from consideration in the discussion below.

An "Ekseavik/Cook Inlet-style" antler harpoon dart head (IYF, Fig. 6b) from Cut F returned a date of $700 \pm 40$ B.P. (A.D. 1260-1310 cal 2 sigma and A.D. 1360-1390 cal 2 sigma), while an "early style" (Giddings 1964:30) antler arrowpoint (IYH1, Fig. 6c) from House 1 returned a date of $580 \pm 42$ B.P. (A.D. $1300-1420$ cal 2 sigma). Cut F is not de- 


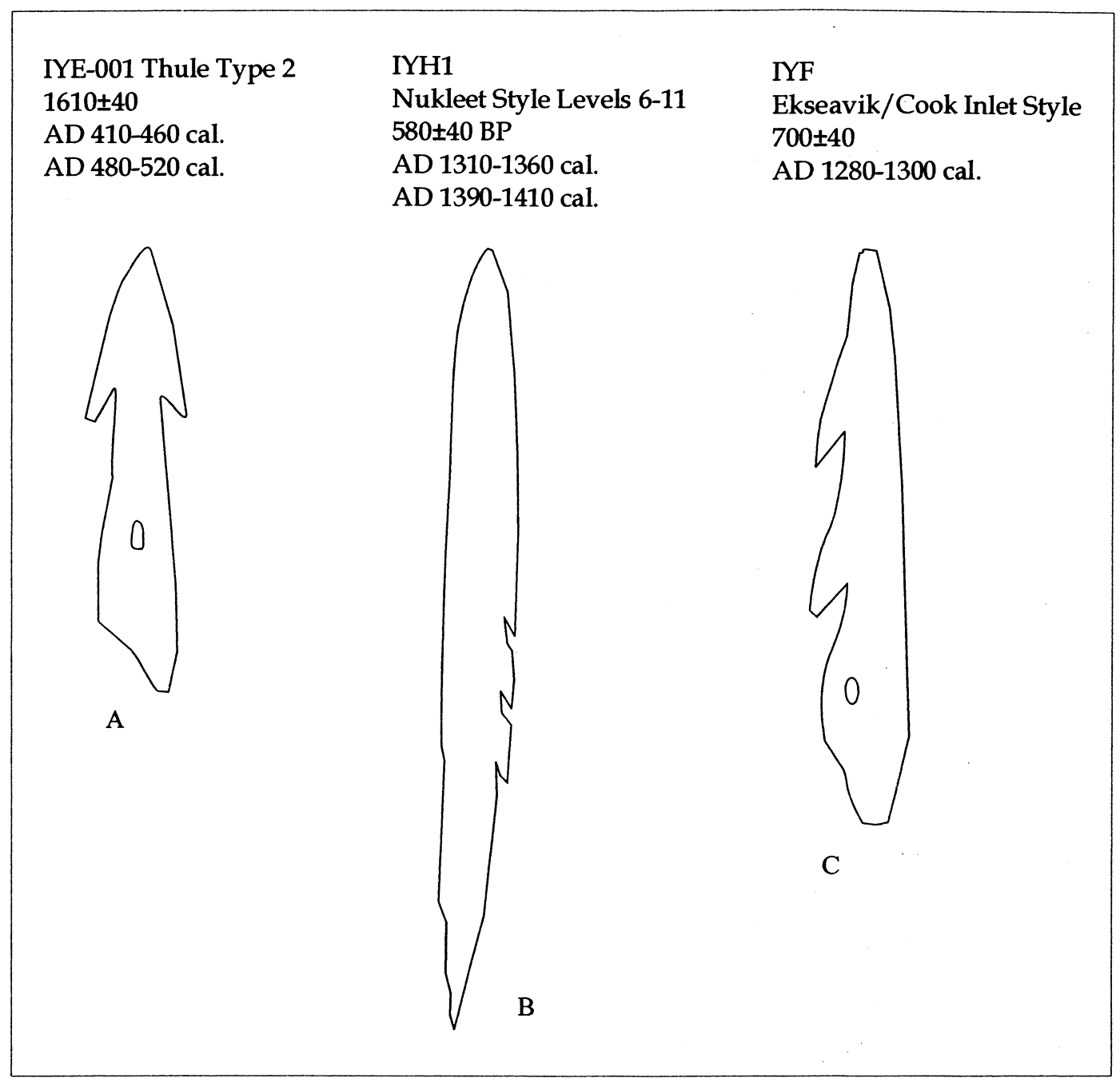

Figure 6. Radiometrically dated artifacts from Iyatayet (not to scale).

scribed in any of Giddings' publications, although House 1 is discussed in some detail (Giddings 1964:124). In the 1948 field season, it was excavated to the floorboards and most of the entrance tunnel and surrounding pit were excavated in 1949 (Giddings 1964:124). Giddings suggested that the house dates to the last period of occupation at the site, roughly A.D. 1600-1700, because it was one of only two house features visible on the site surface. He thought this was an indication of a "terminal building period ...” (Giddings 1964:124). The presence of Intermediate-style Kotzebue or laterstyle Kotzebue-type artifacts on the house floor, and a polished jade adze head similar to seventeenth and eighteenth century examples from the upper Kobuk River (Giddings 1964:124), also suggested a recent date. However, the radiocarbon date on the antler arrowpoint from this house yielded a date of $580 \pm 42$ B.P. (A.D. 1300-1420 cal. 2 sigma), consistent with the dates from the upper levels at Nukleet (A.D. 1405-1520), but several hundred years earlier than Giddings' estimated date of occupation. There are several possible explanations for this discrepancy: 1) use of the house spanned several hundred years, assuming Giddings' estimation of the age of the jade axe head is correct and that axe head styles did not have significant longevity; 2) the estimated age of the house is correct and the antler arrowpoint is a curated piece; and 3) Giddings' estimated age of the house is too recent. The latter explanation seems most fitting since there is no stratigraphic evidence for lengthy or repeated occupation of this feature, and since the other apparently chronologically sensitive artifact-the jade axe head-can only be dated by typological comparison, or by association with dated context. 
The former method is unsatisfactory because we have no indication of the rate of stylistic change for axe heads or for many other late prehistoric Eskimo artifacts (cf. McGhee 1984:90), and at present there are no associated dates on sediments, charcoal, or structural timbers from House 1 that could help to resolve this problem.

The two acceptable dates on antler artifacts from the Nukleet component at Iyatayet fall in the late thirteenth and early fourteenth century, a period during which there may have been an occupational hiatus at Nukleet. As yet there is no radiometric evidence for occupation in the late seventeenth and eighteenth century at either site and at Iyatayet the 4 to 18 inches of grass turf and Subarctic Brown Forest soil that cover the Nukleet component suggest a period of lengthy postaba@्तd donment accumulation (Hopkins and Giddinfs 1953:11). The Nukleet level "is peaty in character, and "organic material is well preserved," at leasहैby comparison to the Norton levels, indicating a climnate slightly cooler than during preceding Nortongูimes (Hopkins and Giddings 1953:25).

\section{î}

\section{No}

Masfon and Gerlach (1995a:105) suggest that 500 B.C $\mathrm{mis}$ the earliest possible age for Norton at Iyataye. The new radiocarbon dates from the overlying ukleet level indicate Norton abandonment of the gite prior to A.D. 1280. Dumond (2000a:4) suggest that the Norton tradition for the entire Bering Seagsirea probably spans 300-400 B.C. to A.D.

100 . Although there is potential for 1,200 years of Norfon site use at Iyatayet, this is probably an inflat\&d estimate and certainly Giddings never suggested such duration of occupation. There is a well-defined sod layer separating most of the Nukleet material from the Norton level (Hopkins and Giddings 1953:21), indicating a substantial abandonment between the two periods (Hopkins and Giddings 1953:2), while elsewhere "Norton assemblages most like . . . Iyatayet date from before about A.D. 100" (Dumond 2000a:5).

Hopkins and Giddings (1953:29) report that one radiocarbon date from the Norton midden at Iyatayet indicates an age of 1500-2000 B.P. or A.D. 1-500. Mason and Gerlach (1995a:103) calibrated a second date (1460 \pm 200 B.P.) on charred wood from the upper Norton levels of Cut PA to A.D. 132-996 cal 2 sigma, a third date (2016 \pm 250 B.P.) on charcoal from House 7 to B.C. $762-557 \mathrm{cal} 2$ sigma, and the average of three dates $(2360 \pm 170$ B.P.) on charcoal from baseline timbers also in House 7 to B.C. 827-A.D. 1 cal 2 sigma. These dates were originally published by Giddings (1962:244-245). As Mason and Gerlach

(1995a:103) point out, all are problematic because of the limitations of the solid carbon technique, and the problem of whole tree bias. Giddings' description of the Norton levels indicates no discernable stratigraphy in the 18-36 inch thick deposit (Giddings 1964:138). A chronology for the Norton occupation at Iyatayet, which is the definitional type-site for the complex, must await direct dates on artifacts and sediments from the appropriate undisturbed Norton levels.

\section{Time, Space, and "Diagnostic" Artifacts}

By directly dating artifacts rather than associated materials, researchers can begin to shed some light on the whether or not the artifact types that have been perceived as chronologically sensitive are, indeed, useful for making temporal distinctions among assemblages and sites on a fine scale, and in the absence of radiometric and other forms of dating. The discussion that follows illustrates this point by focusing on arrowpoints and harpoon heads.

Collins (1937) suggested that arrowpoint form could be used as a means for chronologically ordering archaeological materials from St. Lawrence Island. At Point Hope, Larsen and Rainey (1948: Fig. 51:170) used arrowpoint form to sequence archaeological components, and to determine cultural affiliation. Regarding late prehistoric and historic arrowpoint forms, those apparently diagnostic of Birnirk at Point Hope have "a long cylindrical tang set off from the shoulder by a more or less pronounced tang" (Larsen and Rainey 1948:169) and exhibit considerable variation in body form. Thule arrowpoints have a similar tang but with a raised ridge in the tang middle, although the distinctiveness of this ridge is at best subjective (Larsen and Rainey 1948:172). Arrowpoint forms diagnostic of Tigara have a sharply cut shoulder with a "narrow ridge-formed belt" or "four knobs on the tang" (Larsen and Rainey 1948:176). Forms identical to the Tigara type occur at Ekseavik (Larsen and Rainey 1948:176), which Giddings believed to be later than Ahteut, the latter being contemporaneous with Western Thule. Modern arrowpoint forms from Point Hope parallel Tigara types with the exception that the knobs on the tang number two instead of four, a "feature characteristic of the eastern Thule phase" and attributed to "the return migration” (Larsen and Rainey 1948:179).

Ford (1959:134), following Collins, and Larsen and Rainey, used tang form, along with harpoon 
head styles, to order sites in the Point Barrow region (from oldest to youngest-Birnirk, Nunagiak, Utkiavik, and Nuwuk), with particular reference to Giddings' Kobuk River sequence. Shouldered tang forms characteristic of Utkiavik and Nuwuk are like those from Old Kotzebue (A.D. 1400) and Canadian Thule types (Ford 1959:134-135), while weakshouldered, knobbed tanged forms from Nunagiak are like early Canadian Thule and Ahteut types (A.D. 1250) (Ford 1959:135). At Walakpa, however, Stanford (1976:33) found that different types occurred in the same levels and that the same ownership marks were found on different types raising the possibility that type variability may have been functional or even fortuitous rather than chronological or cultural. Archaeologists place real importance on the Walakpa artifact data, particularly the §̊a arrowpoints and harpoon heads and their placement within the site deposits, for situating other Fo prehistoric sites temporally and culturally in ốcoastal Arctic North America (see for example McCullough 1989; Whitridge 1999). Below we conธิ่ sider Stanford's (1976) position that, despite the 6 -co-occurrence of different types in the same levels Nof the Walakpa deposits, tang and shoulder form are chronologically sensitive as per Collins, Larsen and o Rainey, Giddings, and Ford.

$\overrightarrow{0} \quad$ Following Collins (1937) and based on an exक्. ๖ेWalakpa, Birnirk, Utkiavik, and Cape Prince of

Table 3. Late Prehistoric arrowpoint types: inferred culture and chronological affiliation.

\begin{tabular}{ll}
\hline Arrowpoint & Archaeological Culture and \\
Form* & Location
\end{tabular}

Square shoulder, spurred tang

Sharp shoulder, knobbed tang

Weak or no shoulder, conical, knobbed tang

Tapering tang
Thule, Late Prehistoric Eskimo, Arctic Woodland (Point Barrow, Point Hope, Kobuk River)

Tigara, Thule, Arctic Woodland (Point Barrow, Point Hope, Kobuk River)

Thule, Punuk, Birnirk (Point Barrow, St. Lawrence Island, Kobuk River, Canada)

Birnirk, Old Bering Sea, Okvik, Arctic Woodland (Point Barrow, Point Hope, St. Lawrence Island, Kobuk River)

\section{Temporal Placement According to Kobuk Sequence}

A.D. 1380-1420 (Old Kotzebue)

A.D. $1700-1760$

(Ambler Island)

A.D. $1380-1420$

(Ekseavik)

Type 1: Tapering tang, no knobs, Birnirk only. Type 2: Tapering tang, knobbed, Birnirk, Early Type 3: Conical tang, Late Birnirk, transitional to from Birnirk and Nunagiak.

ype 4. Off-set knobs like Canadian Thule types. Thule, Late Thule.

Type 6: Square shouldered symmetrical knobs, co-occurs with Type 7 including same ownerType 7: Square shoulder with circular knob, Type 8: Square shouldered with knobbed tang, Type 9: Square shoulder with conical knob, Late

Table 3 presents summary information on late prehistoric arrowpoint forms described and af(iliated with particular archaeological cultures and chronological periods as defined by Giddings'

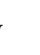
.

Wales in Alaska, Stanford (1976: 34-36) identified Wine types of caribou hunting arrowpoint in these archaeological samples. He suggested that from oldest : 
Table 4. Dated arrowpoints from Nukleet and Iyatayet.

\begin{tabular}{|c|c|c|c|}
\hline Arrowpoint* & $\begin{array}{l}\text { Kobuk } \\
\text { Affiliation* }\end{array}$ & Wider Affiliation** & $\begin{array}{l}\text { Conventional } \\
\text { C-14 Age }\end{array}$ \\
\hline $\begin{array}{l}\text { Square shoulder } \\
\text { Conical tang } \\
\text { Type 4, Nukleet } \\
2543\end{array}$ & $\begin{array}{l}\text { Ekseavik } \\
\text { A.D. } 1380-1420\end{array}$ & $\begin{array}{l}\text { Late Thule } \\
\text { A.D. 1400-1750 }\end{array}$ & $\begin{array}{l}380 \pm 40 \text { B.P. } \\
\text { A.D. } 1450-1520 \\
\text { A.D. } 1590-1620\end{array}$ \\
\hline $\begin{array}{l}\text { Square shoulder } \\
\text { Conical tang } \\
\text { Double barb } \\
\text { Type 3, Nukleet } \\
2555\end{array}$ & $\begin{array}{l}\text { Ekseavik } \\
\text { A.D. 1380-1420 }\end{array}$ & $\begin{array}{l}\text { Late Thule } \\
\text { A.D. } 1400-1750\end{array}$ & $\begin{array}{l}800 \pm 40 \text { B.P. } \\
\text { A.D. } 1210-1270\end{array}$ \\
\hline $\begin{array}{l}\text { No shoulder } \\
\text { Conical tang } \\
\text { Single barb } \\
\text { Type 12, Nukleet } \\
257 \text { हु }\end{array}$ & $\begin{array}{l}\text { Ahteut } \\
\text { A.D. 1200-1250 }\end{array}$ & $\begin{array}{l}\text { Late Birnirk through } \\
\text { Late Thule } \\
\text { A.D. } 800-900 \text { to } \\
\text { A.D. } 1750\end{array}$ & $\begin{array}{l}860 \pm 40 \text { B.P. } \\
\text { A.D. } 1160-1220\end{array}$ \\
\hline 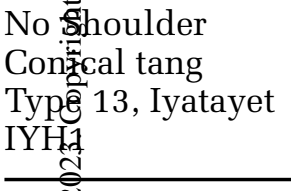 & $\begin{array}{l}\text { Old Style pre-Ahteut } \\
\text { A.D. } 1200-1250\end{array}$ & $\begin{array}{l}\text { Late Birnirk through } \\
\text { Late Thule } \\
\text { A.D. } 800-900 \text { to } \\
\text { A.D. } 1750\end{array}$ & $\begin{array}{l}580 \pm 40 \text { B.P. } \\
\text { A.D. } 1310-1360 \\
\text { A.D. } 1390-1410\end{array}$ \\
\hline
\end{tabular}

*Asddescribed, typed, and dated by Giddings (1952). **After Stanford (1976).

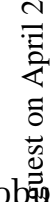

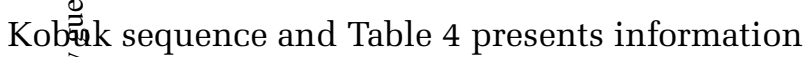
on 恬e newly dated types from Nukleet and Iyat क्व్घet. Even without direct dates on arrowpoints the Summary data demonstrate, as did Stanford (19\%), that types co-occur across space and probably बํำlso across time. "Early" no shoulder, conical tan\&ttypes overlap with "late" shouldered types, andgno type is restricted to a particular archaeological phase. The use of arrowpoints to place sites and features chronologically (see for example Giddings and Anderson 1986:112-113) should be avoided given what is known today. The problem of chronological/cultural affiliation outlined for arrowpoints probably also applies to other artifact forms including harpoon heads, as illustrated below. Table 5 summarizes the radiocarbon dates on harpoon heads from Nukleet and Iyatayet.

The first date on the Ekseavik harpoon head (2657) falls at the end of the proposed range for this artifact style. The second date, on the Intermediate Kotzebue harpoon head (2651), is 110-235 years older than the Giddings' estimated age for Intermediate Kotzebue, and possibly over 700 years younger than the Middle Birnirk phase with which silimar variants are associated (Stan- ford 1976:108). This second harpoon head was recovered from Level 12 at Nukleet, which according to Giddings (1952), dates to the Ekseavik/Old Kotzebue period (A.D. 1380-1420). While the date on the harpoon head (A.D. 1404-1425) is consistent with Giddings' age estimation for the level, it is not consistent with Giddings' age estimation for an Intermediate Kotzebue-style artifact. The third antler harpoon head (2685) that was dated is from Nukleet Cut B, level 13 and it returned a date consistent with Giddings' (1964) estimated age of older than A.D. 1200 for this style, falling as it does between A.D. 1160 and 1290. The fourth date, on ivory, is not considered here due to the problems associated with dating marine mammal remains outlined above. As with arrowpoints, these dates suggests that at least some harpoon head types are quite long lived, in this case perhaps as long as 700 years and again caution is advised in using artifact styles to place sites temporally. Artifacts do not necessarily date sites, sites are not equivalent to complexes, and the sum of a relative sequence of complexes does not equal an historic sequence or a 'cultural' chronology. 
Table 5. Dated harpoon heads from Nukleet and Iyatayet.

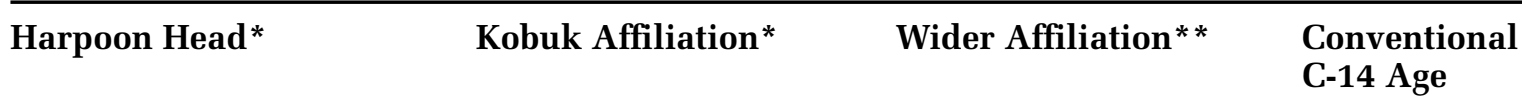

Closed socket

Bladed

Raised Design

Type 4, Nukleet

2657

Closed socket

Self bladed

Plain

Type 1, Nukleet

2651

Closed socket

Bladed

Split spur

¿̊ Type 9, Nukleet

$\pm 2685$

Thule Type $2^{* * *}$

ôIYE
Local Norton Bay

tradition

pre-Ahteut

A.D. $1200-1250$

or earlier

Thule style

Anteut

A.D. 1200-1250
Early Thule

Nuwuk

A.D. 900-1400

$480 \pm 40$ B.P.

A.D. $1420-1455$

Uncertain

Similar to Middle

Birnirk

Thule Type 4

Uncertain

$860 \pm 40$ B.P.

A.D. $1160-1290$
$530 \pm 40$ B.P.

A.D. $1404-1425$

*As described, typed, and dated by Giddings (1952). **After Stanford (1976). ***This specimen is ivory and we believe the date is not reliable, especially for establishing chronologies for type artifacts. FollowEing Dumond and Griffin (2002) it may be as much as $735 \pm 20$ years too old. If Dumond and Griffin are correct, this item could date as recently as A.D. 1035-1115.

\section{Nukleet, Iyatayet, and the Kobuk Sites: Recommendations for Future Research}

Recent proxy climate data derived from the glaciochemical series of the Greenland ice core GISP2 provides the basis for discussing some general trends in Holocene climate, with "quasi -2,600 year intervals of cooling," and increasing regionalization in environmental change (O'Brien et al. 1995:1962). The onset of the Little Ice Age (LIA) in the mid-fourteenth century is the most abrupt of all cooling periods known so far for the Holocene (O’Brien et al. 1995:1962) and was characterized by cold, dry conditions and increased atmospheric circulation (Kreutz et al. 1997:1294). It occurred within a twenty-year period when changes in atmospheric circulation and surface temperature were possibly more dramatic than in any of the previous 4,000 years (Kreutz et al. 1997:1294). The Little Ice Age (LIA) was not a period of continual cooling, but rather was one of both "warm and cold anomalies that varied . . geographically" (Kreutz et al. 1997:1294).
In the Bering Sea intensified storminess postdates the onset of the LIA and periodically reoccurs throughout (Mason et al. 1996:119-120). While site abandonment cannot be directly dated (cf. Cameron and Tomkin 1993), the radiometric data on artifacts from the upper levels of the deposits at Nukleet and Iyatayet suggest the possibility that site use ended during one of these periods of intensified storminess. For example the most recent date from Iyatayet hints at site abandonment following the period between 690 and 560 B.P. (A.D. 1260-1390), while the new dates from Nukleet suggest a possible abandonment following the period between 545 and 430 B.P. (A.D. 1405-1520), perhaps at roughly the same time or slightly later than Iyatayet was abandoned. Geomorphologic data indicate frequent and intense storms at Cape Espenberg at A.D. 1400, 1550-1600, and 1700-1850 (Mason and Gerlach 1995a) and while it is not possible to project directly to Norton Sound and Cape Denbigh from Cape Espenberg, such storms are nonetheless regional (Mason 1990) and may account for the possible abandonment of both Nukleet and Iyatayet during stormy intervals in the LIA. A movement 
away from the Cape Denbigh coast in cold, stormy times would be consistent with the pattern in earlier periods of Alaskan prehistory (Mason and Gerlach 1995a).

Sustained poor weather conditions may have also led to more intensive human settlement in sheltered areas away from Norton Sound altogether. Some of these locations, like the Kobuk River, which, according to Giddings' dendrochronological rendering, sustained a human occupation throughout the LIA, facilitate access to a variety of marine, riverine, and terrestrial resources. Importantly, rivers like the Shaktoolik in Norton Sound and the Kobuk in Kotzebue Sound have cyclically productive and predictable salmon runs. Recent fisheries data from the Kodiak region of Allaska suggest an increase in and sustained levels छ్f long-term sockeye salmon productivity between A.D. 1200-1800, with decadal shifts as the main source of variability (Finney et al. 2002:230). Thi हिए period of sustained productivity continues through the onset of, and well into, the LIA. While coaĝtal marine mammal hunting and open water fishịng may have suffered due to detrimental weạther conditions, salmon harvests would have con rives locations. At least some archaeological data front the Cape Denbigh and the Kobuk River sites sug鸟st further investigation of this proposition wolitd be profitable.

E At Nukleet and Iyatayet, evidence for fishing consists only of "artifacts ... concerned with the taki gig of one fish at time by an individual" while thers is no evidence for extensive netting in the forn of floats, sinkers, and other related tools (Gifdings 1964:47). On the Kobuk River, Ambler Island (A.D. 1700-1760) is the most recent site in Giddings' dendrochronological sequence and the one that may post-date abandonment at Cape Denbigh. The assemblage from the Ambler Island site, which is far up-river, contains no sea-mammal hunting equipment (Giddings 1952) in contrast to collections from sites somewhat further downriver, that are apparently earlier in the sequence. Following Giddings' site chronology this suggests that in earlier periods people settled down river to take advantage of both marine and riverine resources while in later periods settlements moved up-river and people were concerned primarily with taking interior and riverine resources of which salmon of course are an obvious option.

At Onion Portage on the Kobuk River, Anderson (1988:134) interprets the numerous late prehistoric cache pits as salmon storage features reflecting increased use of these fish, perhaps concurrent with a decline in the exploitation of marine mammals as indicated by the absence of sealing harpoon parts. In the absence of an analysis of faunal remains from Onion Portage that would substantiate or refute this interpretation, the best that we can say is that storage would enable people to cope with the annual and interannual fluctuations in salmon resources, while longer-term decadal and century-scale fluctuations might require other strategies (Minc and Smith 1989, Rowley-Conwy and Zvelebil 1989). Anderson (1988:134) attributes increased reliance on salmon in the Kobuk region to the growing use of dog traction and a decline of interior caribou populations (Anderson 1988:151). While this interpretation is possible, increased reliance on salmon also may reflect the inaccessibility of or unreliable access to normally dependable coastal resources, specifically ringed seals, during stormy and cold periods.

In order to test some of these propositions and to further explore the utility of using specific artifact types as chronological markers, the following suggestions are offered. At Nukleet, "type" artifacts from the bottom of Cut B, and from all other cuts should be dated. This will provide further data on the relevance of artifact styles as fine-scale chronological indicators for the late prehistoric period in coastal Arctic North America. Artifact distributions at Nukleet should also be examined to determine if densities vary vertically and horizontally as part of a new line of inquiry into a possible occupation hiatus at the site in the fourteenth century. New fieldwork designed to collect faunal remains and sediments for corroborative dating will provide important information about the length of site formation and the nature of subsistence. With these data, it should be possible to determine whether, as this paper suggests, decreased access to marine resources, possibly as a consequence of sustained changes in local weather conditions, led to movement away from the site during stormy intervals in the fifteenth and sixteenth centuries.

At Iyatayet additional material from House 1 should be dated, as should material from House 6 . House 6 is fully described and inventoried (Henderson 1952) and estimated, on the basis of artifact content and form, to date sometime in the fourteenth century—roughly a phase between Ahteut and Ekseavik on the Kobuk (Henderson 1952). Given the pivotal place of Iyatayet in archaeological sequence development in northwest Alaska, further radiometric dating of both the Norton and 
the Denbigh components at this site and elsewhere is needed. Norton organic artifacts from existing collections can be dated directly, but dating Denbigh will require new fieldwork.

Anderson (1988:134) indicates that the entire Kobuk sequence at Onion Portage is present in Band 1, and he argues that the site is one of the first occupied by Arctic Woodland peoples, citing as an example an Ahteut phase house (13) with two radiometric dates of $900 \pm 50$ B.P. and $1490 \pm 50$ B.P., although he dismisses the latter date as too old for Ahteut but does not explain why. At Cape Krusenstern Giddings and Anderson (1986) also use arrowhead style, among other artifact types, to date house features. For example Houses 50 and 35 are identified by Anderson as Kotzebue period (A.D. 1300-1400) (in Giddings and Anderson ¿ 1986:112). Both contain so-called late arrowpoints (see Giddings and Anderson 1986: Plate 4b, and Plate 5c), identical in tang and shoulder form to ô2555 from Nukleet and dated to A.D. 1160-1290, a period that precedes and overlaps with Ahteut and ¿ิ which is early. Similarly, another identical form was recovered from Recent House 4 on the Choris Peninsula (Giddings and Anderson 1986: Plate 6e) further supporting this paper's contention that at oleast some arrowhead forms are very long-lived. $\vec{s}$ Artifacts thought to be chronologically and culturE. ally sensitive from each site in the Kobuk sequence onneed to be systematically radiometrically dated.

E This will go some way towards establishing which, $\Xi$ if any, of the artifact types are reliably considered Oै temporally diagnostic.

Finally, the extent to which salmon and other fisheries function as a replacement for, or as an alternative to, marine mammal and terrestrial mammal resource use over time and space remains a subject requiring more attention both from archaeologists and biologists. Arguments about the role of climate and weather episodes on resource accessibility and population size are often difficult to link to archaeological events because of lack of temporal resolution of the archaeological data. However, archaeological deposits often contain important data on long-term patterning in human use of marine and terrestrial resources (see for example Cannon 1996, 2000), which is relevant not only to solving problems in prehistory but also to contemporary resource managers and biologists (see for example Finney et al. 2002). Increasingly sophisticated methods of interpreting the nature and duration of archaeological site formation through sediment and radiometric studies indicate that archaeological resolution can be greatly re- fined (Holliday 1993). Thus, it seems advisable to undertake limited excavations designed to recover archaeofauna and sediment samples from sites with a previous history of archaeological investigation but from which such samples were not originally collected. Iyatayet is an excellent example of such a site because it contains long-term data relevant to paleoclimatalogical, paleoecological, paleobiological, and archaeological questions.

\section{Conclusions}

The radiocarbon dated artifacts from Nukleet and Iyatayet suggest two things regarding "diagnostic" artifacts types: 1) it is no longer acceptable to equate certain artifact types with fine-scale (on the order of 50-100 years) temporal phases of late prehistoric occupation along the Kobuk, and 2) in the absence of direct dates on artifact types thought to be diagnostic, many of the Arctic culture history problems with which researchers currently grapple, especially those having to do with culture change and contact (Gerlach and Mason 1992, Mason and Gerlach 1995a, 1995b), are likely to remain unresolved.

A re-examination of the presumed chronologi$\mathrm{cal} /$ cultural affiliation of sites classified according to Giddings' (1952) Kobuk scheme and/or by typological comparison would be profitable. This includes Onion Portage and Cape Krusenstern, if not most other sites in northwest Alaska. When possible, archaeologists should consistently and systematically date both archaeological materials and the deposits from which these materials are recovered. The radiometric dating and re-analysis of existing collections will go a long way towards addressing the numerous archaeological and historical problems in Alaskan archaeology in particular and in Arctic archaeology more generally. The use of arrowpoint and harpoon head styles to date sites is inadvisable in the absence of direct radiometric dates because artifacts styles co-occur across time and space. New fieldwork specifically designed to address some of these problems is also imperative. The controlled reexcavation of some previously explored sites and the testing of known but archaeologically unexplored sites through relatively non-destructive methods of investigation such as coring and augering (Cannon 2000) is also warranted. This is especially the case in regions where the rough outline of human occupation is known and where dated, existing collections can be used as referent material to guide fieldwork designed to address the specific research question outlined above. 
Acknowledgements. Murray would like to thank two anonymous reviewers and Susan Kaplan for helpful comments that significantly improved this paper, and Craig Gerlach for proposing that she undertake this project and re-evaluate both Nukleet and Iyatayet. Many ideas about fine-tuning the chronological sequences in Arctic prehistory in order to examine past human/environment interactions stem from discussions with colleagues in LINK and from discussions with Craig Gerlach. Finally, Murray thanks Rachel Ferrara for her contributions to this paper, and especially Aaron Robertson who developed the artifact dating protocol, resolved some stratigraphic problems with Nukleet and Iyatayet, and pursued the work until it was completed.

Robertson and Ferrara thank the University of Alaska Museum Geist Fund and the Department of nthropology at the University of Alaska Fairbands for supporting this research.

苛Craig Gerlach, Mike Lewis, and James Whitney faciEtated access to the UA Museum collections. Theôstudents in Murray's 1999 “Archaeological Analysis and Interpretation" class, who studied the đUukleet collection, particularly Meg Thornton and Elizabeth Grover, and those in the 2001 class, whơstudied the Ekseavik collection, helped to resol cataloging problems with both collections.

\section{References Cited}

Andersson, Douglas D.

1980 Onion Portage: The Archaeology of a Stratified Site from the Kobuk River, Northwest Alaska. Anthropological Papers of the University of Alaska 22(1-2).

AruPُdale, Wendy $\mathrm{H}$.

198 Radiocarbon Dating in Eastern Arctic Archaeology: A Flexible Approach. American Antiquity 46(2):244-268.

Cannon, Aubrey

1996 Scales of Variability in Northwest Coast Salmon Fishing. In Prehistoric Hunter-Gatherer Fishing Strategies. Mark G. Plew, ed. Pp. 25-40. Boise: Boise State University.

2000 Assessing Variability in Northwest Coast Salmon and Herring Fisheries: Bucket-Augering Sampling of Shell Midden Sites on the Central Coast of British Columbia. Journal of Archaeological Science 27:725-737.

Cameron, Catherine and Stephen Tomkin (eds.)

1993 The Abandonment of Settlements and Regions, Ethnological and Archaeological Approaches. Cambridge: Cambridge University Press.

Collins, Henry B.

1930 Prehistoric Eskimo Culture in Alaska. Smithsonian Institution; Explorations and Field-
Work, 1929. Pp. 147-56. Washington, D.C., Smithsonian Institution.

1937 Archaeology of St. Lawrence Island, Alaska. Smithsonian Miscellaneous Collection, Vol. 96, Number 1. Washington, D.C.: Smithsonian Institution.

Dumond, Don E.

2000a The Norton Tradition. Arctic Anthropology 37(2):1-22.

2000b A Southern Origin for Norton Culture? Anthropological Papers of the University of Alaska 25(1): 87-102.

Dumond, Don E. and Dennis G. Griffin

2002 Measurement of the Marine Reservoir Effect on Radiocarbon Ages in the Eastern Bering Sea. Arctic 55(1): 77-86.

Dyke, Arthur S., Roger N. McNeely, and James Hooper 1996 Mariner Reservoir Corrections for Bowhead Whale Radiocarbon Age Determinations. Canadian Journal of Earth Sciences 33:1628-1637.

Finney, Bruce P., Irene Gregory-Eaves, Marianne S.V. Douglas, and John P. Smol

2002 Fisheries Productivity in the Northeastern Pacific Ocean Over the Past 2,200 Years. Nature 416(18):729-733.

Ford, James A.

1959 Eskimo Prehistory in the Vicinity of Point Barrow, Alaska. Anthropological Papers of the American Museum of Natural History Volume 47, Part 1. New York.

Gerlach, S. Craig and Owen. K. Mason

1992 Calibrated Radiocarbon Dates and Cultural Interaction in the Western Arctic. Arctic Anthropology 29(1):54-81.

Giddings, J. Louis

1952 The Arctic Woodland Culture of the Kobuk River. Museum Monographs, Philadelphia: University Museum.

1962 Onion Portage and Other Flint Sites of the Kobuk River. Arctic Anthropology 1(1):6-21.

1964 The Archaeology of Cape Denbigh. Providence: Brown University Press.

Giddings, J. Louis and Douglas D. Anderson

1986 Beach Ridge Archaeology of Cape Krusenstern: Eskimo and Pre-Eskimo Settlements Around Kotzebue Sound, Alaska. Publications in Archaeology 20, National Park Service. U.S. Department of the Interior. Washington, D.C.

Henderson, Gerald Mitchell

1952 A Neo-Eskimo House Excavation at the Iyatayet Site on Cape Denbigh. Master's thesis, Department of Anthropology, University of Pennsylvania. 
Holliday, Vance T.

1993 Soils in Archaeology: Landscape Evolution and Human Occupation. Washington D.C.: Smithsonian Institution Press.

Hopkins, David M. and J. Louis Giddings

1953 Geological Background to the Iyatayet Archaeological Site, Cape Denbigh, Alaska. Smithsonian Miscellaneous Collections, 121(11). Washington, D.C.: Smithsonian Institution.

Kreutz, K. J., P. A. Mayewski, L. D. Meeker, M. S.

Twickler, S. I. Whitlow, and I. I. Pittalwala

1997 Bipolar Changes in Atmospheric Circulation

during the Little Ice Age. Science 227:1294-1296.

Larsen, Helge and Froelich Rainey

1948 Ipiutak and the Arctic Whale Hunting Culture. Anthropological Papers of the American $\mathrm{Mu}-$ seum of Natural History, vol. 42. New York.



1989 The Ruin Islanders: Early Thule Culture Pioneers

in the Eastern High Arctic. Canadian Museum of Civilization, Mercury Series, Archaeological

Survey of Canada Paper 141, Hull.

McGhee, Robert

1984 The Thule Village at Broomin Point, High Arctic Canada. National Museums of Canada, Mercury Series, Archaeological Survey of Canada Paper 125, Ottawa.

McGhee, Robert and James A. Tuck

1976 Un-Dating the Canadian Arctic. In Eastern Arctic Prehistory: Paleoeskimo Problems. Moreau S. Maxwell, ed. Pp. 6-14. Memoirs of the Society for American Archaeology, no. 31.

Mason, Owen K.

1990 Beach Ridge Geomorphology of Kotzebue Sound: Implications for Paleoecology and Archaeology.

Ph.D. dissertation, Department of Quaternary Science, University of Alaska Fairbanks.

Mason, Owen K. and S. Craig Gerlach

1995a Chukchi Hotspots, Paleo-Polynyas, and Caribou Crashes: Climatic and Ecological Dimensions of North Alaska Prehistory. Arctic Anthropology 32(1):101-130.

1995b The Archaeological Imagination, Zooarchaeological Data, the Origins of Whaling in the Western Arctic and "Old Whaling" and Choris Cultures. In Hunting the Largest Animals: Native Whaling in the Western Arctic and Subarctic. Allen P. McCartney, ed. Pp. 1-31. Studies in Whaling, no. 3, Occasional Publication no. 36. Edmonton: Canadian Circumpolar Institute.

Mason, Owen K., David K. Salmon, and Stefanie Ludwig 1996 The Periodicity of Storm Surges in the Bering Sea from 1898 to 1993 Based on Newspaper Accounts. Climatic Change 43:109-123.
Mathiassen, T.

1927 Archaeology of the Central Eskimos: The Thule Culture and its Position within the Eskimo Culture. Report of the Fifth Thule Expedition, 1921-1924:4. Copenhagen: Glydendalski Boghandel, Norisk Forlag.

Mills, Robin O.

1994 Radiocarbon Calibration of Archaeological Dates from the Central Gulf of Alaska. Arctic Anthropology 31(1):126-149.

Minc, Leah and Kevin P. Smith

1989 The Spirit of Survival: Cultural Responses to Resource Variability in North Alaska. In Bad Year Economics: Cultural Responses to Risk and Uncertainty. Paul Halstead and John O'Shea, eds. Pp. 8-39. Cambridge: Cambridge University Press.

Morrison, David

1989 Radiocarbon Dating Thule Culture. Arctic Anthropology 26:48-77.

2001 Radiocarbon Dating the Birnirk-Thule Transition. Anthropological Papers of the University of Alaska, NS 1(1): 73-85.

Nash, Stephen E.

2000 James Louis Giddings' Archaeological Tree-Ring Dating in the American Arctic: A Forgotten Legacy. Arctic Anthropology 37(1):60-78.

O’Brien, S. R., P. A. Mayewski, L. D. Meeker, D. A. Meese, M. S. Twickler, and S. I. Whitlow

1995 Complexity of Holocene Climate as Reconstructed from a Greenland Ice Core. Science 270:1962-1964.

Rowley-Conwy, Peter and Marek Zvelebil

1989 Saving it for Later: Storage by Prehistoric Hunter-Gatherers in Europe. In Bad Year Economics: Cultural Responses to Risk and Uncertainty. Paul Halstead and John O'Shea, eds. Pp. 40-56. Cambridge: Cambridge University Press.

Stanford, Dennis J.

1976 The Walakpa Site, Alaska: Its Place in the Birnirk and Thule Cultures. Smithsonian Contributions to Anthropology, Number 20. Washington, D.C.: Smithsonian Institution.

Whitridge, Peter J.

1999 The Construction of Social Difference in a Prehistoric Inuit Whaling Community. Ph.D. dissertation, Department of Anthropology, Arizona State University. 